\title{
Examining retail purchases of cigarettes and nicotine replacement therapy in Finland
}

\author{
David S. Timberlake ${ }^{1,2}$, Johanna Joensuu' ${ }^{1}$, Terhi Kurko ${ }^{3}$, Arja H. Rimpelä ${ }^{1,4,5}$, Jaakko Nevalainen
}

\begin{abstract}
INTRODUCTION Finland's success in achieving the goal of its tobacco endgame largely depends on rectifying deficiencies in the delivery of smoking cessation services. One such weakness, which has not been documented with empirical data, is misuse of nicotine replacement therapy (NRT). This study's objective was to examine purchase patterns of NRT for estimating improper use of the medication. The study was based on the assumption that duration of a purchase episode is indicative of either proper use or misuse of NRT.

METHODS The participants $(\mathrm{n}=728)$, who purchased at least one NRT product in 2016 (mostly gum/lozenge), were selected through enrollment in a large customer loyalty program in Finland (LoCard). Participants were categorized into one of five groups according to their longest purchase episode of NRT, defined by purchases made in consecutive, 4-week intervals.

RESULTS Most participants, who did not adhere to NRT guidelines, either purchased the medication for too short ( $\leq 4$ weeks, $63.5 \%$ ) or too long ( $>24$ weeks, $13.2 \%$ ) of a purchase episode. Median purchases of NRT in the first month of use were one and four in the former and latter, respectively. In contrast to other groups, persistent users ( $>24$ weeks) did not curtail purchases of NRT across several 4-week intervals, suggesting potential for dependence on NRT.

CONCLUSIONS The observation that most purchase episodes were terminated prematurely is consistent with surveys reporting widespread NRT misuse. Given uncertainty of greater regulation of NRT sales through legislation, it would be prudent for Finnish retailers to promote proper use of the therapy.
\end{abstract}

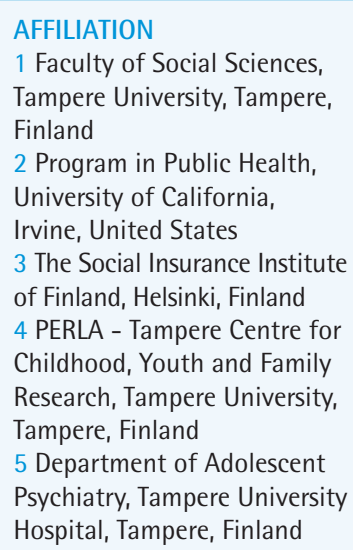

CORRESPONDENCE TO

David S. Timberlake. Program in Public Health, University of California, Anteater Instruction \& Research Offices, Irvine, CA, United States

E-mail: dtimberl@uci.edu

\section{KEYWORDS}

nicotine replacement therapy, cigarettes, tobacco endgame, time-series data, retail purchases

Received: 16 November 2018 Revised: 30 March 2019 Accepted: 15 April 2019

\section{INTRODUCTION}

Providing nicotine replacement therapy (NRT) to smokers without a doctor's prescription, via an over-the-counter (OTG) purchase, was a significant initiative to increase accessibility and use of the proven therapy ${ }^{1}$. Critics argue that easier access to the medication reduces the interaction between patient and provider, which is critical for a successful quit attempt. Others contend that even after prescribing medication, physicians seldom provide proper cessation counseling ${ }^{2,3}$. In countries such as Finland, pharmacists provided counseling because OTC sales of NRT were initially restricted to pharmacies. But, the Finnish Parliament approved a law that deregulated the NRT market in 2006, allowing retail sales in grocery stores, kiosks and gasoline stations ${ }^{4}$. Prices of NRT products, which declined by $15 \%$ after deregulation, were the least expensive in hypermarkets, followed by 
supermarkets and pharmacies ${ }^{5}$. Consequently, sales of NRT increased dramatically in Finland ${ }^{6}$, but not in pharmacies $^{7}$ where consultation occurs on the proper use of the medication.

The initial concern about liberalizing the NRT market focused on smokers' potential for prolonging use of the medication beyond the 3-month period set by the US Food and Drug Administration (FDA). This concern was largely dispelled by studies reporting that only $6 \%$ of participants purchased and used NRT for an extended period of at least six months ${ }^{8,9}$. It is believed that most smokers prolong their use of NRT in order to quit or reduce smoking rather than satiate an addiction. Consequently, researchers advocated that guidelines for duration of NRT use be extended beyond the 3 -month maximum ${ }^{10,11}$. A more pressing issue relates to the majority of smokers who prematurely terminate the use of $\mathrm{NRT}^{12}$. Using a longitudinal design, Zhang et al. ${ }^{12}$ reported that smokers who used NRT for less than four weeks had a decreased likelihood of achieving abstinence relative to the non-NRT users (OR=0.51, 95\% CI: 0.38-0.67). The ineffectiveness of using NRT for such a brief period is concerning because studies, such as the ITC Four-Country Survey ${ }^{13}$, indicate that OTC NRT is prematurely terminated among the majority of users. Balmford et al. ${ }^{13}$ reported that $62.9 \%$ and $76.3 \%$ of users of OTC NRT had only used the medication for $\leq 4$ weeks and $\leq 8$ weeks, respectively. Such studies, however, are limited by the use of self-reported data that cannot be verified. The alternative of analyzing time-series purchases is one means of obviating the inaccuracies that occur with survey data. The current study used retail data for estimating the percentage of NRT users who purchased the medication for too short or too long of a purchase episode.

An examination of retail purchases is particularly needed in light of Finland's goal to end the use of tobacco by 2030 (i.e. $<5 \%$ prevalence). The Roadmap to a Tobacco-Free Finland specifies several steps in treating tobacco dependence ${ }^{14}$ as part of the larger goal of rectifying deficiencies in smoking cessation services. As evidence of one such deficiency, Finland received the low score of $5 / 10$ points for tobacco treatment on the 2016 Tobacco Control Scale ${ }^{15}$. One notable recommendation in the Roadmap is to reimburse smokers for medications and remove Section 54a from the Medicines Act, the latter permitting sales of OTC NRT in retail outlets (e.g. grocery stores). The absence of purchase data, which predates the deregulation of Finland's NRT market in 2006, precludes assessment of whether purchases from retail outlets contribute to greater misuse of NRT relative to purchases from pharmacies. The current study is neither designed to test effectiveness of regulated versus deregulated NRT markets, nor is it designed to examine patterns of use and motives for purchasing NRT. Instead, this study aims to examine the duration of NRT purchase episodes for estimating the duration of episodes of NRT use. The goal is to verify the extent of NRT misuse ${ }^{13}$ through estimation of purchase episodes that are terminated prematurely. The findings could serve as baseline estimates in the case of future policy change, and provide retailers information that could facilitate efforts to increase customers' adherence to NRT guidelines.

\section{METHODS}

\section{Sample selection}

Participants of this study were selected through their enrollment in a customer loyalty program headed by the S Group, a commercial enterprise possessing more than $45 \%$ of the market share in Finland ${ }^{16}$. The S Group's large market share minimizes but does not negate the possibility that study participants could have purchased cigarettes and NRT from other sources. Using a database containing customers' email addresses, the S Group contacted members of the customer loyalty program in the HOK-Elanto retail co-operative in southern Finland. The email inquiry sought members' consent to release basic demographic information (age, gender, postal code) and purchases made in the year 2016. Release of the data, which excluded personal identifiers, was intended for research purposes and approved by the ethics committee of the University of Helsinki Review Board in the humanities and social and behavioral sciences. Approximately $5 \%$ of members of the loyalty program consented to the data release, yielding a sample of 13274 customers. Compared to the general population in southern Finland, consenting members of the loyalty program were predominantly female (about 68\%), middle-aged (about 46 years old), and more educated, which can be attributed to higher participation rates ${ }^{16}$. This is evidenced by the statistic indicating that $56 \%$ versus $33 \%$ of consenting loyalty 
members and the general population, respectively, had a university degree ${ }^{17}$. Our final analytic sample, which excluded S Group personnel, consisted of customers who purchased at least one NRT product in the year $2016(n=728)$.

\section{Measures}

The measures were the time, date, and expenditures of cigarettes and NRT in the year 2016. Categories of NRT consumers were based on the purchase of one or more products in consecutive 4 -week intervals. The categories, which were based on clinical guidelines and empirical findings ${ }^{12}$, correspond to: the early terminators ( $\leq 4$ weeks of use); those who used NRT for the minimum period (5-8 weeks); those who used NRT for the standard recommended period (9-12 weeks); those who extended their use of NRT according to revised recommendations (13-24 weeks $)^{10}$; and those who exceeded the maximum period of NRT use ( $>24$ weeks). The study participants were categorized into one of the five mutually exclusive groups according to their longest purchase episode, absent a purchase lapse exceeding 28 days. For example, if a participant had purchased NRT on 5 February, 21 February and 16 March, and made a subsequent purchase on 9 June, then the participant was classified as having purchased NRT for 5-8 weeks of use (range: 29-56 days). For those participants who had multiple but equal purchase episodes, the longest episode in days was selected. An interruption in the purchase of NRT exceeding one month was used previously in signifying a new episode of use ${ }^{9}$. Our classification scheme did not account for those who made bulk purchases of NRT for use over a lengthy time period. Furthermore, the classification scheme was not based on incident purchases, and, thus, does not necessarily represent individuals who used NRT for the first time. For example, an early terminator who made a purchase in January 2016 may have purchased NRT throughout the latter part of 2015.

Based on sales data from the S Group, nicotine gum and lozenge constituted $96.9 \%$ of the total sales volume of all nicotine replacement products. Sales of the nicotine patch, which were low and unchanging from 2006 (deregulation) through $2013^{6}$, were slightly higher in pharmacies compared to other outlets. Given its low overall volume, it is unlikely that the nicotine patch was supplemented with copious purchases of nicotine gum and lozenge. Data released by the S Group included neither the product type (e.g. gum, lozenge, patch) nor product characteristics such as brand, package size, or dosage in milligrams. Expenditures of NRT were available for analysis, but, overlapped too much to differentiate product types. Thus, we opted not to extrapolate package size from expenditure for estimating the supply of NRT for use over a designated period. Instead of extrapolating package size, we used consecutive purchases over 4-week intervals as a measure of duration of NRT use, which does not imply that the purchase(s) provided a sufficient supply of NRT for any given month. Although expenditures of NRT were not used in extrapolating package sizes, they were summed over intervals as a descriptive way of illustrating purchase differences among the five groups of NRT consumers.

\section{Data analysis}

The data analyses entailed the use of paired and non-paired statistical tests. Non-parametric methods were employed due to the skewed distributions of purchases and expenditures of NRT and cigarettes. The Kruskal-Wallis test on ranks, analogous to a one-way ANOVA, was used for comparing purchases and expenditures across the five groups of NRT consumers. One notable comparison across groups was the number of NRT purchases made in the first four weeks of a purchase period. The Wilcoxon signed rank test was used for testing differences within pairs across time periods, by NRT consumer group. Purchases in the first four weeks served as the baseline for comparisons to purchases made in subsequent 4 -week intervals. The within-pair tests facilitated assessment of whether NRT purchases stayed the same or diminished following the first four weeks of a purchase episode.

\section{RESULTS}

\section{Characteristics of NRT consumers}

The 728 participants made a total of 9300 NRT and 21601 cigarette purchases in 2016. Most purchases of NRT and cigarettes occurred on Friday, making up $16.2 \%$ and $17.4 \%$ of total sales, respectively. A higher per cent of females versus males $(66.9 \%$ vs $57.0 \%)$ and young versus the old ( $72.9 \%$ vs $61.6 \%)$ prematurely terminated use of NRT. Tests of independence 
indicated a statistically significant association between NRT consumer group and $\operatorname{sex}\left(\chi_{(4)}^{2}=10.8 ; \mathrm{p}=0.03\right)$, but not age group $\left(\chi_{(8)}^{2}=10.5 ; p=0.3\right)$ (Table 1).

The early terminators, who did not make consecutive purchases across 4-week intervals, composed almost two-thirds of the entire sample. Of the NRT products, $15.2 \%$ and $11.6 \%$ were purchased by the early terminators during January 2016 and the other eleven months of the year $\left(X_{(1)}^{2}=7.8 ; p=0.005\right)$, respectively, suggesting that several early terminators may have purchased the medication as part of a New Year's resolution. Among the early terminators $(n=462)$,
237 had purchased NRT only one time with a median expenditure of $€ 6.6$ (range: $€ 2-€ 30.1$ ). These onetime purchasers of NRT frequently purchased cigarettes as evidenced by a high median number of cigarette purchases (31) and cigarette expenditures (€251.8).

The participants who exceeded NRT recommendations ( $>24$ weeks, $n=96$ ), referred to as persistent users, had the fewest cigarette purchases due in part to the large per cent $(50 \%)$ of users who did not make a single cigarette purchase in 2016. The persistent users had a median purchase gap of NRT that was half the value observed in those who bought NRT

Table 1. Characterizing consumers of nicotine replacement therapy (NRT) by their demographics and purchases of NRT and cigarettes in $2016(n=728)$

\begin{tabular}{|c|c|c|c|c|c|c|c|}
\hline & \multirow[t]{2}{*}{ N/I groups } & \multicolumn{5}{|c|}{ Calegories of VRT Consumers } & \multirow[t]{2}{*}{ Test statistic } \\
\hline & & \begin{tabular}{c|} 
Early \\
termination
\end{tabular} & Vlinimum & Recommended & Exrtended & Exceeded & \\
\hline Sample size & 728 & 462 & 66 & 43 & 61 & 96 & \\
\hline $\begin{array}{l}\text { Duration of NRT use } \\
\text { defining group }\end{array}$ & & $\begin{array}{c}\leq 4 \\
\text { weeks }\end{array}$ & $\begin{array}{c}5-8 \\
\text { weeks }\end{array}$ & $\begin{array}{l}9-12 \\
\text { weeks }\end{array}$ & $\begin{array}{l}13-24 \\
\text { weeks }\end{array}$ & $\begin{array}{l}25-52 \\
\text { weeks }\end{array}$ & \\
\hline \multicolumn{8}{|l|}{ Demographics } \\
\hline \multicolumn{8}{|l|}{ Sex $(\%)$} \\
\hline Female & 64.8 & 68.4 & 51.5 & 58.1 & 55.7 & 65.6 & \multirow{2}{*}{$X_{(4)}^{2}=10.8^{*}$} \\
\hline Male & 35.2 & 31.6 & 48.5 & 41.9 & 44.3 & 34.4 & \\
\hline \multicolumn{8}{|l|}{ Age group (\%) } \\
\hline$<30^{\mathrm{b}}$ & 9.6 & 11.0 & 10.6 & 4.6 & 9.8 & 4.2 & \multirow{3}{*}{$X_{(8)}^{2}=10.5$} \\
\hline $30-49$ & 58.5 & 58.0 & 56.1 & 72.1 & 49.2 & 62.5 & \\
\hline$\geq 50$ years & 31.9 & 31.0 & 33.3 & 23.3 & 41.0 & 33.3 & \\
\hline \multicolumn{8}{|l|}{ NRT Purchases } \\
\hline $\begin{array}{l}\text { Median purchases/ } \\
\text { year }\end{array}$ & 3 & 1 & 10 & 12 & 23 & 49 & $X_{(4)}^{2}=530^{* * *}$ \\
\hline $\begin{array}{l}\text { Median purchases/ } \\
\text { period }^{c}\end{array}$ & 2 & 1 & 4 & 6 & 13 & 43.5 & $X_{(4)}^{2}=578^{* * *}$ \\
\hline $\begin{array}{l}\text { Purchase gap in } \\
\text { days }^{c, d}\end{array}$ & 9 & 12 & 12.7 & 12 & 8 & 6 & $X_{(4)}^{2}=82.5^{* * *}$ \\
\hline \multicolumn{8}{|l|}{ NRT Expenditures $(€)$} \\
\hline Median/year & 32.3 & 13.6 & 90.1 & 155.7 & 233.3 & 633.0 & $X_{(4)}^{2}=466^{* * *}$ \\
\hline Median/period ${ }^{c}$ & 21.6 & 9.1 & 40.6 & 69.4 & 145.7 & 585.1 & $X_{(4)}^{2}=480^{* * *}$ \\
\hline \multicolumn{8}{|l|}{$\begin{array}{l}\text { Cigarette Purchases } \\
\text { ct Expenditure }\end{array}$} \\
\hline \% Purchased in 2016 & 67.6 & 71.6 & 65.1 & 67.4 & 67.2 & 50.0 & $X_{(4)}^{2}=17.2^{* *}$ \\
\hline $\begin{array}{l}\text { Median purchases/ } \\
\text { year }\end{array}$ & 24 & 27 & 34 & 18 & 17 & 11 & $X_{(4)}^{2}=4.6$ \\
\hline $\begin{array}{l}\text { Median expenditures } \\
(€) / \text { year }\end{array}$ & 180.4 & 211.9 & 224.0 & 105.5 & 105.2 & 91.4 & $X_{(4)}^{2}=7.2$ \\
\hline
\end{tabular}

a Categories are defined according to purchases made in consecutive 4-week intervals (see Methods), b Includes small number of adolescents ( $\mathrm{n}=18$ ), c Corresponds to the period defining each group, $d$ Median was calculated from the distribution of medians of individual participants, excluding those who purchased NRT only one time, e Limited to those who made a cigarette purchase in $2016(n=492)$, $f$ Kruskal-Wallis test for non-parametric data (one-way ANOVA on ranks). ${ }^{*} p<0.05$, ${ }^{* *} p<0.01,{ }^{* *} p<0.0001$. 
over the recommended period ( 6 vs 12 ; for all groups, $\left.\chi_{(4)}^{2}=82.5 ; \mathrm{p}<0.0001\right)$. The purchase gaps were assessed within periods of consecutive NRT purchases (gaps $\leq 28$ days), thus negating the possibility that large gaps could be attributed to a later purchase of NRT. Almost $5 \%$ of the entire sample $(n=35)$ had purchased NRT for 13 consecutive 4-week intervals in 2016.

\section{Purchases of NRT over time}

For the first month of use, purchases of NRT varied significantly across the five groups of consumers $\left(X_{(4)}^{2}=416.9 ; \mathrm{p}<0.0001\right)$, with the median purchase ranging from one to four in the early terminators and persistent users, respectively (Table 2 ). Similar purchase patterns were observed across the NRT consumer groups for the subsequent 4-week intervals. In examining within-pair differences, we observed statistically significant declines in NRT purchases from baseline (i.e. first four weeks of a purchase episode) to the subsequent 4 -week intervals in the groups using NRT over the minimum, recommended, and extended time periods. For example, those who followed minimum recommendations had a median of three purchases in the first month of use, but only 1.5 purchases in weeks five through eight $(S=624.5 ; p<0.001)$. Declines following the first four weeks of purchasing NRT were evident for every group with exception those who exceeded the guidelines. The latter had a median of four purchases in weeks 1-4, weeks 5-8, weeks 9-12, and weeks 13-16. By weeks 25-28, a significant decline in NRT purchases from baseline had been observed ( $S=760.5 ; p<0.001)$. Yet, the persistent users' purchases and expenditures were rather stable over the whole period.

Table 2. A comparison of the quartiles of NRT expenditures and quartiles of number of NRT purchases (in parenthesis) across groups of consumers by four-week periods of NRT use

\begin{tabular}{|c|c|c|c|c|c|c|}
\hline \multirow{2}{*}{$\begin{array}{l}\text { - Week Period } \\
\text { of NRT Use }\end{array}$} & \multirow[t]{2}{*}{ Percentile } & \multicolumn{5}{|c|}{ Categories of VRT Consumers } \\
\hline & & $\begin{array}{c}\text { Early } \\
\text { termination } \\
\text { I weeks } \\
(\text { n - 162) }\end{array}$ & $\begin{array}{c}\text { Vinimum } \\
5 \text { - } 8 \text { weeks } \\
(\text { in }-66)\end{array}$ & $\begin{array}{c}\text { Recommended } \\
9-12 \text { weeks } \\
(n-13)\end{array}$ & $\begin{array}{l}\text { Extended } \\
1321 \text { weeks } \\
\text { (n-61) }\end{array}$ & $\begin{array}{l}\text { Exceeded } \\
25-52 \text { weeks } \\
(n-96)\end{array}$ \\
\hline \multirow{3}{*}{ Weeks $1-4^{* * *}$} & $25 \%$ & $5.2 €(1)^{\mathrm{a}}$ & $15.2 €(2)$ & $17.7 €(2)$ & $21.7 €(2)$ & $29.8 €(3)$ \\
\hline & $50 \%$ & $9.1 €(1)$ & $23.3 €(3)$ & $35.4 €(3)$ & $39.2 €(3)$ & $56.0 €(4)$ \\
\hline & $75 \%$ & $20.1 €(2)$ & $44.7 €(4)$ & $52.0 €(4)$ & $55.3 €(5)$ & $89.7 €(6)$ \\
\hline \multirow{4}{*}{ Weeks $5-8^{* * *}$} & $25 \%$ & $N A^{b}$ & $6.6 €(1)$ & $10.0 €(1)$ & $16.8 €(2)$ & $32.6 €(3)$ \\
\hline & $50 \%$ & NA & $15.8 €(1.5)$ & $19.9 €(2)$ & $30.2 €(3)$ & $55.5 €(4)$ \\
\hline & $75 \%$ & NA & $34.0 €(2)$ & $43.1 €(3)$ & $43.7 €(4)$ & $83.8 €(6.5)$ \\
\hline & \multicolumn{2}{|c|}{ Signed rank test } & $\mathrm{S}=624.5^{* *}$ & $S=206.5^{* *}$ & $S=157^{*}$ & $\mathrm{~S}=77.5$ \\
\hline \multirow{3}{*}{ Weeks $9-12^{* * *}$} & $25 \%$ & NA & NA & $10.0 €(1)$ & $15.0 €(2)$ & $30.0 €(3)$ \\
\hline & $50 \%$ & NA & NA & $18.5 €(1)$ & $29.4 €(2)$ & $50.4 €(4)$ \\
\hline & $75 \%$ & NA & NA & $30.0 €(2)$ & $43.2 €(4)$ & $85.8 €(6)$ \\
\hline \multicolumn{3}{|c|}{ Signed rank test } & & $\mathrm{S}=267^{* *}$ & $\mathrm{~S}=349^{* *}$ & $S=321.5$ \\
\hline \multirow{4}{*}{ Weeks ${ }^{\mathrm{c}} 13-16^{* * *}$} & $25 \%$ & NA & NA & NA & $14.9 €(2)$ & $26.0 €(3)$ \\
\hline & $50 \%$ & NA & NA & NA & $29.9 €(2)$ & $53.7 €(4)$ \\
\hline & $75 \%$ & NA & NA & NA & $38.6 €(3)$ & $88.5 €(6)$ \\
\hline & \multicolumn{2}{|c|}{ Signed rank test } & & & $S=316.5^{* *}$ & $\mathrm{~S}=175$ \\
\hline \multirow{4}{*}{ Weeks' 25-28 } & $25 \%$ & NA & NA & NA & NA & $20.8 €(2)$ \\
\hline & $50 \%$ & NA & NA & NA & NA & $47.4 €(3)$ \\
\hline & $75 \%$ & NA & NA & NA & NA & $72.7 €(5)$ \\
\hline & \multicolumn{2}{|c|}{ Signed rank test } & & & & $S=760.5^{* *}$ \\
\hline
\end{tabular}

a Each cell represents the quartile 1st (25\%), 2nd (50\%), or 3rd (75\%) of NRT expenditures in euros and quartile of number of NRT purchases (in parenthesis), b Not applicable, c The 4-week period was selected because everyone within the respective NRT group had purchased NRT during the specified period. ${ }^{* * *} p<0.0001$ corresponds to a Kruskal-Wallis test on ranks of NRT purchases across groups of consumers; ${ }^{* *} p<0.001$ and ${ }^{*} p<0.05$ correspond to the Wilcoxon signed rank test of NRT purchases across 4 -week periods, using the first four weeks of a purchase episode as the baseline comparison. 


\section{Concurrent purchases of cigarettes and NRT}

The percentage of concurrent purchases of cigarettes and NRT in the first and last month of a purchase episode, shown in Figure 1, excludes the participants who never purchased cigarettes in 2016. Concurrent purchases were coded in terms of pairs of consecutive purchases of the two products. For example, if a customer purchased a cigarette pack on day 5 , another cigarette pack on day 17, and NRT on day 20, then a single concurrent purchase would be coded as having occurred within the same week. In this way, the coding scheme selected the shortest period between a cigarette and NRT purchase.
In their single month of NRT use, the early terminators had a lower percentage of concurrent purchases relative to other groups, which occurred despite frequent purchases of cigarettes throughout the year. Concurrent purchases on the same day or same week, which occurred frequently for the other groups, changed slightly among those who purchased NRT over minimum and extended periods. In contrast, the decline in the percentage of concurrent purchases on the same day/week was more evident for those who followed recommendations $(75.7 \%$ to $56.8 \%)$ and those who exceeded recommendations $(75.2 \%$ to $63.7 \%)$.

Figure 1. Concurrent purchases of cigarettes and NRT in the first month ( $\mathrm{n}=\mathbf{8 4 4}$ purchases) and last month (n=286 purchases) of a purchase episode

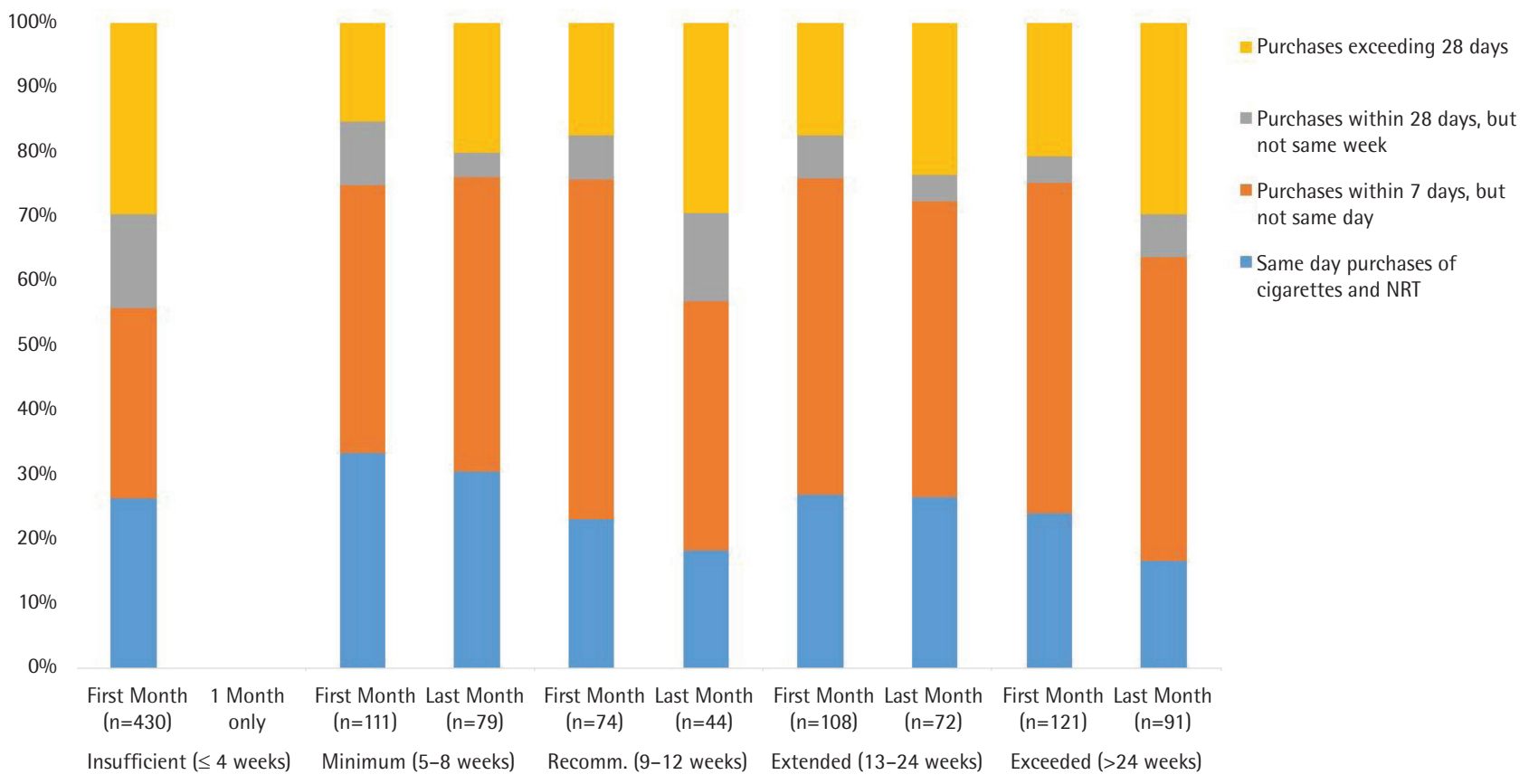

\section{DISCUSSION}

The study's findings suggest that most consumers in Finland are not purchasing NRT over a sufficient period of time. Our estimate of those who purchased NRT for four weeks or less $(63.5 \%)$ is remarkably similar to use of the medication over the same period reported from the ITC Four-Country Survey $(62.9 \%)^{13}$. The current study also revealed that the amount of NRT purchased in the first four weeks of a purchase episode was very small in those who terminated early relative to those who proceeded to purchase NRT over lengthier periods. The correlation between amount and duration of NRT purchases could be indicative of success or failure of a cessation attempt ${ }^{18}$.

As reported in other studies ${ }^{13,19}$, the two most commonly cited explanations for prematurely terminating NRT use, relapse to smoking and medication side effects, are legitimate reasons according to manufacturers' guidelines. A third explanation may be traced to smokers' concerns about becoming dependent on NRT. Some smokers from Finland, who participated in an online forum (i.e. STUMPPI quitline $)^{20}$, advocated the strict and 
limited use of NRT in an effort to avoid nicotine dependence. Yet, the same smokers acknowledged that such practice could lead to an unsuccessful quit attempt. In our study, it is likely that many early terminators failed to quit smoking as a function of their frequent cigarette purchases and dependence on nicotine. A fourth explanation for early termination could be traced to improper NRT use arising from lack of instruction and guidance. One study reported that among US smokers who used nicotine gum, only $58 \%$ read any of the product inserts ${ }^{21}$.

Our estimate of the NRT purchases exceeding 24 weeks $(13.2 \%)$ was higher than expected. The most likely explanation is that the US study, which reported $6 \%$ of participants who purchased NRT for a minimum of six months ${ }^{9}$, estimated incidence of persistent use, whereas, our study estimated prevalence of persistent use. Some persistent users identified in our study in 2016 probably used NRT throughout 2015, leading to a higher estimate than that reported by Shiffman et al. ${ }^{9}$. Another explanation for our higher estimate is the European guideline recommending the extended use of $\mathrm{NRT}^{22}$. In contrast, the study conducted by Shiffman et al. ${ }^{9}$ was conducted prior to the US FDA's recommendation to extend duration of NRT use ${ }^{10}$. It is notable that $71.6 \%$ versus $50 \%$ of the early terminators and persistent users, respectively, had purchased cigarettes in 2016. While we do not know the smoking status of those who did not purchase cigarettes, it is likely that most were former smokers who replaced their habit with pharmaceutical nicotine. Current knowledge suggests that persistent use of NRT is less harmful than smoking cigarettes. Unlike other groups in our study, the persistent users did not curtail their use of NRT for several weeks following initiation of a purchase episode. While this is a concern, dependence on oral NRT is an uncommon occurrence ${ }^{23}$.

In lieu of an amendment to the Medicines Act, retailers could take a number of actions to increase customers' adherence to NRT guidelines. They could, for example, increase customers' exposure to the guidelines through the dissemination of more instructional brochures. Another option, which is currently being discussed by the S Group, is an online database of purchases of customers enrolled in the loyalty program. At the moment, consideration is being given to tracking grocery purchases for improving the health and nutrition of customers.
If such a database were to be developed, then NRT purchases could be readily added along with recommendations for increasing customers' proper use of the medication. An online feature would be particularly useful because of the high per cent of young customers ( $<30$ years old) who use the Internet but do not properly use NRT. While any one of these retailer initiatives could modify consumer behavior, they are not proven as effective interventions.

\section{Limitations}

The time-series analysis of retail purchases of cigarettes and NRT minimized the measurement error that frequently occurs in survey data. Yet, there are limitations that need to be acknowledged with regard to using purchase data. First, the cigarette and NRT purchases could have been used by someone other than the purchaser, such as a family member. Data indicating more than one smoker per smoking household ${ }^{9}$ suggest the possibility of multiple quit attempts within the same household. Consequently, single purchasers of NRT within such households could have inflated our estimate of NRT purchases per customer. The second limitation is that a loyalty member may have purchased NRT in an S Group market, but purchased cigarettes elsewhere (or vice versa); consequently, neither smoking status nor prevalence of NRT use could be determined. Third, our categorization of NRT consumer groups was based on purchase episodes in 2016, not purchase incidents. This limitation precluded us from estimating an individual's risk of becoming a persistent user of NRT. We could not determine if the longest purchase episode of NRT occurred in 2016, or some period prior to 2016. Further, we could not determine if an individual who purchased NRT in the latter part of 2016 continued to purchase NRT throughout 2017.

An additional limitation was the inability to assess whether the study's findings can be generalized from the sample of loyalty members who purchased NRT to the population of NRT consumers in southern Finland. One surrogate measure for purchasing NRT is smoking status. Yet, the absence of data on smoking status in the sample and population precluded us from weighting our estimates according to population proportions of smokers and non-smokers. Since the highly educated were oversampled in our study, it is likely that any such weighting scheme would 
have yielded a proportion of early terminators of NRT that exceeded the proportion reported in the current study. Yet, in the absence of a weighting scheme, the estimate for early termination of therapy was already inflated by the higher percentage of female customers (who were oversampled) versus male customers who terminated purchases of NRT prematurely. In contrast, Balmford et al. ${ }^{13}$ reported that female smokers had greater odds, though nonsignificant, than male smokers of completing a course of treatment $(\mathrm{OR}=1.24,95 \% \mathrm{CI}: 0.95-1.61)$.

The absence of product type (e.g. gum, lozenge) and product characteristics (e.g. package size) precluded an accurate assessment of whether a consumer purchased a sufficient amount of NRT to cover a 4-week period. The alternative of using more detailed data from Nielsen Company's Homescan Consumer Panel was not an option because of the insufficient number of participating households in Finland ( $n=5000$; pers. comm. Ethan Markovitz, Manager, Client Solutions, Nielsen). Even if more detailed data were available, such information would not have accounted for the variability in daily use of oral NRT 9 .

\section{CONCLUSIONS}

This study supports findings from survey data indicating that most users of NRT terminate the therapy prematurely. In the latest proposal to end tobacco use in Finland by the year 2030, a working group commissioned by the Ministry of Social Affairs and Health recommended amending the Medicines Act for greater monitoring of the distribution channels of OTC NRT ${ }^{24}$. Yet, given the uncertainty of any amendment to the Act, it would be prudent for retailers to take steps to increase customers' knowledge of proper NRT use and awareness of NRT purchases.

\section{REFERENCES}

1. Shiffman S, Sweeney CT. Ten years after the Rx-toOTC switch of nicotine replacement therapy: what have we learned about the benefits and risks of nonprescription availability? Health Policy. 2008;86(1):1726. doi:10.1016/j.healthpol.2007.08.006

2. Shiffman S, Ferguson SG, Hellebusch SJ. Physicians' counseling of patients when prescribing nicotine replacement therapy. Addict Behav. 2007;32(4):728-739. doi:10.1016/j.addbeh.2006.06.021
3. Solberg LI, Asche SE, Boyle RG, Boucher JL, Pronk NP. Frequency of physician-directed assistance for smoking cessation in patients receiving cessation medications. Arch Intern Med. 2005;165(6):656-660. doi:10.1001/archinte.165.6.656

4. Kurko T, Linden K, Vasama M, Pietila K, Airaksinen M. Nicotine replacement therapy practices in Finland one year after deregulation of the product sales--has anything changed from the community pharmacy perspective? Health Policy. 2009;91(3):277-285. doi:10.1016/j.healthpol.2008.12.013

5. Aalto-Setala, V and A Alaranta. Effect of deregulation on the prices of nicotine replacement therapy products in Finland. Health Policy. 2008. 86(2-3): p. 355-62. doi:10.1016/j.healthpol.2007.11.013

6. Kurko T. Deregulation of Nicotine Replacement Therapy Products in Finland: Reason for Pharmaceutical Policy Changes and Reflections on Smoking Cessation Practices. Finland: University of Helsinki; 2005.

7. National Agency of Medicines and Social Insurance Institution. Sales of nicotine replacement therapy products. Helsinki, Finland: F.S.o. Medicines; 2007.

8. Shiffman S, Hughes JR, Di Marino ME, Sweeney CT. Patterns of over-the-counter nicotine gum use: persistent use and concurrent smoking. Addiction. 2003;98(12):17471753. doi:10.1111/j.1360-0443.2003.00575.x

9. Shiffman S, Hughes JR, Pillitteri JL, Burton SL. Persistent use of nicotine replacement therapy: an analysis of actual purchase patterns in a population based sample. Tob Control. 2003;12(3):310-316. doi:10.1136/tc.12.3.310

10. Fucito LM, Bars MP, Forray A, Rojewski AM, Shiffman S, Selby P, West R, Foulds J, Toll BA, Writing Committee for the SRNT Policy and Treatment Networks. Addressing the evidence for FDA nicotine replacement therapy label changes: a policy statement of the Association for the Treatment of Tobacco use and Dependence and the Society for Research on Nicotine and Tobacco. Nicotine Tob Res. 2014;16(7):909-914. doi:10.1093/ntr/ntu087

11. Zapawa LM, Hughes JR, Benowitz NL, Rigotti NA, Shiffman S. Cautions and warnings on the US OTC label for nicotine replacement: what's a doctor to do? Addict Behav. 2011;36(4):327-332. doi:10.1016/j.addbeh.2010.12.003

12. Zhang B, Cohen JE, Bondy SJ, Selby P. Duration of nicotine replacement therapy use and smoking cessation: a population-based longitudinal study. Am J Epidemiol. 2015;181(7):513-520. doi:10.1093/aje/kwu292

13. Balmford J, Borland R, Hammond D, KM Cummings. Adherence to and reasons for premature discontinuation from stop-smoking medications: data from the ITC FourCountry Survey. Nicotine Tob Res. 2011;13(2):94-102. doi:10.1093/ntr/ntq215

14. Ministry of Social Affairs and Health. Roadmap to a TobaccoFree Finland: Action Plan on Tobacco Control. Helsinki, Finland: Ministry of Social Affairs and Health; 2014. 
15. Joossens L, Raw M. The Tobacco Control Scale 2016 in Europe. Belgium, Brussels: A.o.E.C. Leagues; 2017.

16. Nevalainen J, Erkkola M, Saarijarvi H, Nappila T, Fogelholm M. Large-scale loyalty card data in health research. Digit Health. 2018;4. doi:10.1177/2055207618816898

17. Preliminary and unpublished data from the LoCard data collection for 2016-2018, 2019.

18. Raupach T, Brown J, Herbec A, Brose L, West R. A systematic review of studies assessing the association between adherence to smoking cessation medication and treatment success. Addiction. 2014;109(1):35-43. doi:10.1111/add.12319

19. Burns EK, Levinson AH. Discontinuation of nicotine replacement therapy among smoking-cessation attempters. Am J Prev Med. 2008;34(3):212-215. doi:10.1016/j.amepre.2007.11.010

20. Kurko T, Linden K, Kolstela M, Pietila K, Airaksinen M. Is nicotine replacement therapy overvalued in smoking cessation? Analysis of smokers' and quitters' communication in social media. Health Expect. 2015;18(6):2962-2977. doi:10.1111/hex.12280

21. Bansal MA, Cummings KM, Hyland A, Giovino GA. Stop-smoking medications: who uses them, who misuses them, and who is misinformed about them? Nicotine Tob Res. 2004;6(Suppl 3):S303-310. doi:10.1080/14622200412331320707

22. Royal College of Physicians. Harm reduction in nicotine addiction: Helping people who can't quit. London, England: Royal College of Physicians; 2007.

23. Hughes JR, Pillitteri JL, Callas PW, Callahan R, Kenny M. Misuse of and dependence on over-the-counter nicotine gum in a volunteer sample. Nicotine Tob Res. 2004;6(1):79-84. doi:10.1080/14622200310001656894

24. Ministry of Social Affairs and Health: Smoke-free Finland through better tobacco and nicotine policy. https://stm. fi/artikkeli/-/asset_publisher/tyoryhma-tupakka-janikotiinipolitiikkaa-kehittamalla-suomi-savuttomaksi. Accessed May 31, 2018.
ACKNOWLEDGEMENTS

The authors thank the $S$ Group for the use of retail purchases from members of the customer loyalty program. The primary author thanks the Fulbright Finland Foundation for providing salary and other resources which made this project possible. We thank three anonymous reviewers for their helpful suggestions.

\section{CONFLICTS OF INTEREST}

The authors declare that they have no competing interests, financial or otherwise, related to the current work. T. Kurko is a member of the working group appointed by the Finnish Medical Society Duodecim and the Finnish Association for General Practice of the Tobacco and Nicotine Dependency, Prevention and Treatment Current Care Guideline. The rest of the authors have also completed and submitted an ICMJE form for disclosure of potential conflicts of interest.

\section{FUNDING}

The study was supported by the Finland Fulbright Foundation.

\section{AUTHORS' CONTRIBUTIONS}

D.S.T., J.J. and J.N. formulated the hypothesis and analytical methodology. D.S.T. and J.J. coded the data and conducted the statistical analyses. T.K. and A.H.R. provided policy insight, guidance on clinical recommendations and patterns of N.R.T. use typically observed in practice. D.S.T. wrote most of the manuscript and J.J., T.K., A.H.R. and J.N. provided critical review and editing.

PROVENANCE AND PEER REVIEW

Not commissioned; externally peer reviewed. 